\title{
Cuidado ao idoso em Campinas-SP: estudo qualitativo com gestores e representantes políticos
}

\author{
Care to the elderly in Campinas-SP: qualitative study of managers and politicians
}

Atención a los ancianos en Campinas-SP: estudio cualitativo envolviendo administradores y políticos

\author{
Déborah Cristina de Oliveira', Eliete Maria Silva" \\ ' Universidade Estadual de Campinas, Faculdade de Ciências Médicas, Programa de Pós-Graduação \\ em Enfermagem (Mestranda). Campinas-SP, Brasil. \\ "Universidade Estadual de Campinas, Faculdade de Ciências Médicas, Departamento de Enfermagem, \\ Programa de Pós-Graduação em Enfermagem. Campinas-SP, Brasil.
}

Submissão: 10-07-2011 Aprovação: 22-01-2013

\section{RESUMO}

O estudo busca identificar, descrever e analisar as práticas pertinentes à saúde do idoso na cidade de Campinas-SP, na perspectiva de representantes da saúde do idoso, tendo como base a Política Nacional de Saúde à Pessoa Idosa. Estudo qualitativo, com análise temática de conteúdo, na perspectiva de sujeitos que assumem funções estratégicas na condução da política direcionada ao idoso no município. A partir dos depoimentos dos sujeitos emergiram cinco temas centrais: tempos e lugares; condições de acesso; demandas da população; recursos humanos; promoção à saúde e prevenção de doenças e agravos; gestão. As práticas voltadas à saúde do idoso em Campinas estão em desenvolvimento e precisam ser avaliadas, ampliadas e sistematizadas, tanto nas questões estruturais de recursos humanos, financiamento e gestão, quanto na atenção direta ao idoso.

Descritores: Idoso; Políticas Públicas; Serviços de Saúde; Enfermagem.

\begin{abstract}
The study aimed to identify, describe and analyze the practices carried out in the health of the elderly in the city of Campinas-SP, in the perspective of the health government representatives of the elderly, based on the National Policies. This is a qualitative study with thematic content analysis, from the perspective of individuals who assume strategic roles in the conduct of policy directed to the elderly in the county. Five central themes emerged from their comments: time and places; access conditions; population demands; human resources; health promotion and prevention of diseases and disorders; management. Health practices for the elderly health in Campinas-SP are in development, need to be evaluated, extended and systematized in both, the structural issues of human resources, finance and management, and in direct assistance to the elderly.
\end{abstract}

Key words: Aged; Public Policies; Health Services; Nursing.

\section{RESUMEN}

El estudio busca identificar, describir y analizar las prácticas llevadas a cabo en la salud de las personas mayores en la ciudad de Campinas-SP, en la perspectiva de representantes de la salud de los ancianos, basado en el Política Nacional. Estudio cualitativo con análisis de contenido temático, desde la perspectiva de las personas que asumen roles estratégicos en la conducción de la política dirigida a las personas mayores en el condado. A partir de sus declaraciones, fueran identificados cinco temas centrales: tiempo lugares; condiciones de acceso; demandas de la población; recursos humanos; promoción de la salud y prevención de enfermedades y trastornos; gestión. Las practicas de salud para los ancianos en Campinas-SP se encuentran en desarrollo, necesitan ser evaluadas, ampliadas y sistematizadas, tanto en los aspectos estructurales de los recursos humanos, finanzas y administración, así como en la asistencia directa a las personas mayores.

Palabras clave: Anciano; Políticas Públicas; Servicios de Salud; Enfermería.

Extraído de Trabalho de Conclusão de Curso apresentado, em 2009, ao Departamento de Enfermagem da Faculdade de Ciências Médicas da Unicamp. 


\section{INTRODUÇÃO}

O Brasil tem vivenciado um processo de aumento da expectativa de vida decorrente da rápida transição demográfica nos últimos anos ${ }^{(1-2)}$.

Dados da Pesquisa Nacional por Amostra de Domicílios do Instituto Brasileiro de Geografia e Estatística, de 2008, apontam que a proporção de idosos no Brasil com pelo menos uma doença crônica é de 79,1\%. Além disso, 30,5 \% dos idosos não tem seu domicílio cadastrado no Programa Saúde da Família nem possuem plano de saúde particular ${ }^{(3)}$.

As altas demandas em saúde pela população frente aos recursos públicos escassos e finitos implicam, invariavelmente, formas de priorização para sua utilização correta, eficaz, eficiente e efetiva e também moralmente legítima ${ }^{(4)}$. Promover a saúde com equidade torna-se, assim, um grande desafio para os gestores públicos, pois os níveis de desigualdades sociais em saúde e os recursos escassos fazem com que as prioridades para a gestão pública se fundamentem no conhecimento da situação de saúde e do impacto de políticas, programas, projetos e ações sobre a saúde e seus determinantes ${ }^{(5)}$.

A equidade em saúde exige métodos de planejamento que privilegiem o uso de recursos potencialmente benéficos para melhorar a saúde de toda a população. Nesta perspectiva, para que o impacto social seja ampliado, as ações deveriam atingir o maior número possível de pessoas, priorizando a redução de doenças comuns ${ }^{(5)}$. Além disso, o cuidado ao idoso implica oferecer serviços cuja estrutura apresente características que possibilitem o acesso e acolhimento adequado a estas pessoas, respeitando suas vulnerabilidades e especificidades ${ }^{(6)}$.

Para nortear a criação e o desenvolvimento de práticas em prol da saúde dos idosos no país, criou-se a Política Nacional de Saúde da Pessoa Idosa (PNSPI) ${ }^{(7)}$, que fundamenta a ação do setor saúde na atenção integral à população idosa nos diferentes níveis de atendimento: promoção da saúde, prevenção, recuperação e tratamento das doenças.

Em outubro de 2003 foi instituído o Estatuto do $\operatorname{Idoso}^{(8)}$, que prescreve diretrizes para o cuidado com o objetivo de prevenir doenças e manter a saúde dos idosos. Conta com 118 artigos sobre diversas áreas dos direitos fundamentais, incluídas as necessidades de proteção, visando reforçar as diretrizes contidas na Política Nacional do Idoso, delineada a partir de 1994. Além de incluir leis e políticas já aprovadas, incorpora novos elementos e enfoques, dando um tratamento integral ao estabelecimento de medidas destinadas a proporcionar $\mathrm{o}$ bem-estar.

A garantia dos direitos sociais dos idosos não tem se concretizado efetivamente, pois estas políticas vêm sendo implementadas no Brasil de forma lenta e gradativa ${ }^{(9)}$. Assim, faz-se necessário identificar as práticas implantadas nos municípios que tenham por objetivo seguir estas políticas, refletindo e avaliando o trabalho realizado pelas equipes de saúde, considerando a aplicabilidade e resolubilidade.

Portanto, o presente estudo teve por objetivos identificar, descrever e analisar as práticas realizadas na saúde do idoso na cidade de Campinas-SP, na perspectiva de representantes da saúde do idoso, tendo como base a PNSPI.
Este trabalho busca fomentar discussões acerca das concepções dos sujeitos sobre estas práticas, pela identificação de questões da saúde do idoso, no contexto político e social e subsidiar intervenções no ensino, na pesquisa e na assistência, podendo contribuir para a Enfermagem e para o crescimento e aperfeiçoamento das práticas e políticas de saúde neste campo.

\section{MÉTODOS}

Trata-se de um estudo exploratório, descritivo e analítico, com abordagem qualitativa, realizado por meio de entrevistas semiestruturadas com trabalhadores, gestores e representantes da saúde do idoso na cidade de Campinas - SP. Envolvemos os responsáveis em âmbito distrital, no serviço especializado e também no Conselho Municipal do Idoso, conforme segue.

Distritos de saúde: a cidade de Campinas conta com cinco distritos de saúde, divididos de acordo com o território da cidade. São eles: distrito Norte, Noroeste, Sul, Sudoeste e Leste. Cada um deles contém determinado número de serviços de saúde pelos quais são responsáveis. Foram entrevistados quatro apoiadores da saúde do idoso, um de cada distrito, com exceção do distrito sul, pois a apoiadora estava em férias no período da coleta de dados.

Centro de Referência a Saúde do Idoso da Cidade de Campinas-SP: localizado no centro da cidade, esta unidade foi criada pela Prefeitura de Campinas e é a primeira unidade de referência de Campinas voltada para a saúde da população idosa. Foi entrevistado um gestor deste serviço.

Conselho Municipal do Idoso (CMI): o Conselho Municipal do Idoso é um órgão vinculado à Prefeitura Municipal de Campinas e que foi criado com os objetivos de interpretar e veicular os interesses da população idosa, tendo como meta a formulação, coordenação, supervisão e avaliação das políticas e práticas municipais dirigidas a essa parcela da população. Foi entrevistado um representante deste órgão.

Secretaria de Saúde: Foi entrevistada a profissional responsável pela Área de Assistência à Saúde do Idoso na SMS de Campinas, ligada ao Departamento de Saúde.

A coleta de dados foi realizada no período de julho a setembro de 2009, em encontros previamente marcados com os sete sujeitos. Foram explicados os objetivos do estudo e como seria realizada a entrevista. Também assinaram neste momento o Termo de Consentimento Livre e Esclarecido (Resolução 196/96, Conselho Nacional de Saúde), aprovado pela Secretaria Municipal de Saúde de Campinas e pelo Comitê de Ética em Pesquisa da Faculdade de Ciências Médicas da Universidade Estadual de Campinas (Unicamp), Campinas, São Paulo, Parecer $n^{\circ} 451 / 2009$. As entrevistas foram realizadas por uma das autoras do trabalho.

Para a coleta de dados foi elaborado um roteiro semiestruturado, elaborado em duas partes. A primeira relacionada aos dados de caracterização dos sujeitos: nome, sexo, idade, formação, local de trabalho, tempo de atuação no trabalho. A segunda parte continha perguntas temáticas, ou seja, sobre as práticas voltadas à saúde do idoso. Desta forma o participante era estimulado a trazer conteúdos relacionados às práticas implementadas no município e em sua área de atuação. 
A formulação de cada uma das perguntas foi feita com base nas diretrizes da PNSPI: promoção à saúde e manutenção da capacidade funcional, atenção às necessidades de saúde do idoso, apoio a estudos e pesquisas na área do envelhecimento e capacitação de recursos humanos especializados. Além disso, solicitou-se aos sujeitos uma avaliação geral da saúde do idoso em Campinas (SP), e a indicação de dificuldades para o desenvolvimento das ações e possíveis alternativas.

Para análise dos discursos, utilizou-se o método de análise temática de conteúdo, que consiste em descobrir os núcleos de sentido que compõem uma comunicação cuja presença ou frequência signifiquem algo para o objetivo analítico visado. Ou seja, tradicionalmente, a análise temática se encaminha para a contagem de frequência das unidades de significação como definitórias do caráter do discurso(10).

Nessa perspectiva, as entrevistas foram todas gravadas em fitas cassete e transcritas na íntegra, os sujeitos receberam o nome das sete cores do arco-íris como forma de identificação, preservando assim o anonimato de suas identidades. As entrevistas foram codificadas inicialmente em categorias ou temas centrais. As ações e interações entre as diversas categorias iniciais foram relacionadas, reclassificando-as para melhorar a clareza e abrangência dos relatos.

A discussão dos dados foi feita com vista a tornar mais claras as concepções dos gestores acerca da política e avaliar as ações no âmbito da saúde do idoso, compreendendo de forma mais viva e direta o modo como os sujeitos deste estudo pensam sobre a sua prática para a população idosa de Campinas (SP).

\section{RESULTADOS}

Foram entrevistados sete representantes da saúde do idoso no município. Destes, cinco eram do sexo feminino. A faixa etária variou dos 31 aos 59 anos. Quanto à formação, cinco são médicos (um pediatra, três geriatras e um sanitarista), um enfermeiro e um deles é administrador de empresas. O tempo de atuação atual no cargo de representante ou gestor variou de três meses a cinco anos.

Os temas centrais identificados foram: tempos e lugares; condições de acesso; gestão; recursos humanos; demandas da população; promoção à saúde e prevenção de doenças e agravos.

\section{A. Tempos e lugares}

Este tema relaciona-se com a necessidade dos sujeitos de descreverem sua realidade numa perspectiva histórica. Constam aqui menções a trabalhadores que foram marcantes para o desencadeamento de práticas e diretrizes municipais na saúde do idoso, trazem algumas das características dos distritos e a ideia de que o trabalho na área da saúde do idoso em Campinas é novo e está em desenvolvimento:

Eu acho que ele é muito novo (...) ele é bem recente com relação às políticas a nível central que foram criadas e depois levadas para a base. (Amarelo)
O distrito $Z$ avançou muito, pois um dos apoiadores, o (...), se interessou muito por esta área (...). Então ele se apropriou disso como dele. Se apropriou mais no que pôde e junto aos outros apoiadores do distrito ele desencadeou algumas ações. (Laranja)

Há uma área de abrangência antiga e uma área muito nova. Naquela tem-se mais idosos que nesta. Quanto mais longe do centro, menos idosos. (Azul)

\section{B. Condições de Acesso}

Algumas entrevistas enfatizaram a questão das instalações precárias para o atendimento do idoso, seja em situações de emergência, seja em Centros de Saúde, tanto em relação ao acesso dos usuários com alterações de locomoção, quanto em relação à privacidade, com ocorrências de interrupção de atividades que necessitam de ambiente privado, em depoimentos, como:

Quando o paciente [idoso] não é tão grave, mas precisa de uma observação mais prolongada ou internação, eles são levados para o (...), mas não tem um ambiente, um espaço para receber melhor o idoso. (Violeta)

Trazem também a necessidade de se investir em infraestrutura para que a população de idosos possa ser atendida adequadamente e que as ações em saúde a este segmento populacional sejam integrais e universais, conforme deve ser o SUS para todos.

Tem um grupo que até acabou, por conta de espaço físico (...). Então, as atividades ao ar livre são mais fáceis porque a gente acaba usando as praças, salões de igrejas (...). Um dos Centros de Saúde tem dificuldade de acesso porque ele fica num prédio que não tem acesso para cadeira de rodas, nem elevador... (Verde)

\section{Demandas da população}

Este tema mostrou ser um dos maiores entraves na questão atendimento ao idoso em Campinas. A demanda de idosos que buscam o centro de saúde é grande quando se consideram os recursos disponíveis para atendê-los. Muitos subtemas estiveram relacionadas dentro deste tema, e um deles é a intensa procura das unidades de saúde por parte dos idosos:

(...) Se você for aos grupos de trabalho, a maioria é de idosos, acima de 60 anos, aposentados, ou, então, donas de casa... (Verde)

Além disso, relatam que a Estratégia Saúde da Família abriu portas para muitos problemas sociais e de saúde que antes eram pouco identificados, além do cuidador, que hoje é um dos principais desafios para os serviços de saúde no município, pois demandam cuidados e têm necessidades complexas. Os sujeitos mostram que estão desenvolvendo alternativas para suprir esta demanda: 
Com a ajuda dos Agentes Comunitários de Saúde (ACS) (...) a gente achou muito caso de abandono e negligência (...) e aí trouxe outra demanda que acabou ficando grande demais para nós, que é a questão do cuidador informal (...). A gente tem aqui no distrito esse manual de cuidadores (...). Então aqui a gente faz esses grupos. Antes a gente fazia 'in loco', a capacitação do cuidador junto com as unidades. Agora, o ano passado nós optamos por capacitar multiplicadores... (Verde)

Agora, a nossa dificuldade é com aqueles cuidadores que ainda nem sequer se assumiram, no seu papel e estão nos seus domicílios... Muitas vezes são também pessoas jovens, trabalhadoras, que também não podem vir ao Centro de Saúde nestes horários que a gente faz, às vezes, param de trabalhar, mas não tem com quem deixar o idoso para vir (...). A nossa penetração neste campo ainda, eu acho, é muito falha; e outra, (...) se a gente não faz um trabalho com o adulto jovem, para que ele tenha percepção de si mesmo e de sua saúde, como que a gente quer que ele tenha esta percepção do outro. (Violeta)

Outro problema envolve a rede privada de saúde. Trata-se do fato de muitos convênios de saúde oferecerem o serviço de atendimento domiciliar ao idoso, mas não fornecerem o material para o cuidado, que fica por conta das famílias ou das unidades básicas. Além disso, muitos pacientes têm perdido seus convênios por conta da piora da situação econômica da família, ou porque perdem seus empregos ou quando se aposentam:

(...) A gente tem sentido que a população de idosos 'SUS dependente' tem crescido nos últimos tempos, por uma questão econômica mesmo (...). Então, assim: o convênio faz atendimento domiciliar, mas não dá o insumo. Então, a gente fornece gaze, material para o curativo e eles fazem a assistência. Então, tem muito paciente acamado no distrito que a gente tem registrado, mas não dá assistência direta... É muito complicado. Então, a gente não pode parar de fornecer porque o paciente tem direito, é da área de abrangência. Ao mesmo tempo você não está vendo a qualidade da assistência que ele está recebendo, não tem controle disso. (Verde)

E com a alta demanda de pacientes idosos com problemas de saúde surgem dúvidas sobre como priorizar o acesso dos usuários aos serviços que ainda é insuficiente:

(...) (a saúde para o idoso em Campinas) precisa ser ampliada e mantida. Você tem dificuldade no atendimento em saúde, por exemplo, com o idoso que não tem recursos... Têm idosos em situação em emergência, é um exemplo, e a família leva esse idoso a um atendimento médico. Aí quando ele tem alta, ele não tem nem condição de voltar sozinho para casa... Não tem quem o leve... Não tem quem cuide dele... (Anil)

Porque a gente tem dificuldade de garantir acesso para população às consultas... em geral... Então a gente tenta fazer grupos, outras portas de entrada que não a consulta. Mas uma hora o idoso vai precisar de uma assistência mais especializada pelos profissionais. Então por mais que façamos grupos, isso vai permitir que alguns não adoeçam, mas os que adoecerem não estarão tão bem amparados... (Verde)

Quando a gente tem poucos agentes a gente tenta dividir por risco, obviamente as áreas de maior risco e a gente tenta varrer estas áreas, e as de menor risco a gente vai ver com o tempo, fica para depois. É assim: não que a gente deixe de reconhecer a universalidade, mas temos que trabalhar com a equidade. (Violeta)

\section{Recursos humanos}

Com relação à questão dos recursos humanos em saúde os participantes trouxeram muitas questões que estão relacionadas à má qualidade no atendimento ao idoso, a falta de contratação de pessoal, equipes incompletas, o absenteísmo, o estabelecimento e acompanhamento de competências, por exemplos:

Apesar de a gente valorizar no discurso esta questão da promoção, quando a gente vai ver (...) o nosso quadro de recursos humanos não favorece (...) e hoje a gente tem isso, equipe de saúde da família, clínico, e vai esse 'feijão com arroz'. Mas a gente sabe que se a gente quiser investir pesado em promoção de saúde, esse modelito, a gente precisa inovar um pouco mais. (Violeta)

Este absenteísmo compromete todo o trabalho programado para aquele dia, aquela semana, (Laranja)

Agora, se eu sei que o ACS está fazendo Lian Gong, está fazendo grupo: não é para isso! Não é que ele não seja capaz de fazer, mas é que ele está tendo um 'desvio' de sua função, (Laranja)

A educação oferecida aos profissionais, intitulada de "capacitação", parece ser fortemente focada na abordagem da doença no idoso em detrimento do processo de saúde-doença-cuidado com manutenção da funcionalidade e independência desses indivíduos. Alguns gestores criticaram esta ideia, no entanto, foi evidente também a percepção de que idoso é bem tratado, pois ele tem as mesmas "doenças" do adulto:

... a gente está fazendo esta capacitação. Mas capacitação em algumas patologias mais prevalentes: demência, Parkinson, osteoporose, dor... (Amarelo)

O objeto do nosso trabalho é algo altamente complexo, que tem uma dimensão de subjetividade muito grande (...). Por exemplo, nos grupos de diabéticos, o paciente vai lá e ouve: 'o diabetes é uma doença assim, você não pode fazer isso e aquilo... Ele não tem mais vontade de viver! Eu não preciso vir aqui para escutar isso, é só ligar a televisão que eu 
vejo! Eu quero vir num lugar que me leve para cima e que me fale: 'olha, isso aqui não é bom, mas esta outra aqui é bem legal, dá para viver bem, enfim (...). Muitos profissionais ainda veem este modelito... Apesar de que isso é muito difícil, é uma mudança de cultura profissional (...). E aí eu incentivo todas as nossas unidades a fazer uma abordagem não só técnica da hipertensão, do diabetes; mas cuidar, antes, do processo saúde-doença: de discutir, o que é a vida, o que é doença, o que é crescer, envelhecer, o que é ter um envelhecimento saudável, (...) Obviamente, vai ter um momento em que a gente vai falar de hipertensão, diabetes, medicamentos, enfim. (Violeta)

... Olha, a maioria está preparado para atender sim, por conta da patologia que eles apresentam: diabetes, hipertensão, enfim, todas as outras (...). (Azul)

Eu acho que as pessoas ainda não estão capacitadas para atender o idoso de forma adequada... (Verde)

E, além disso, tem a conscientização dos profissionais que eu acho que isso vem com as capacitações (...). Tem para o adulto, para mulher, e para direcionar um pouco mais para o idoso, porque falta ainda uma sensibilidade mesmo para o idoso no dia-a-dia, né... (Vermelho)

Ainda neste tema os sujeitos relatam haver pouco envolvimento da prefeitura com pesquisas e estudos na área do envelhecimento por parte do município, sendo este tema, na maioria das vezes, tocado apenas pelas iniciativas das universidades. Queixam-se da falta de sensibilização por parte dos profissionais no que diz respeito às peculiaridades da saúde do idoso, ao mesmo tempo, é possível identificar uma preocupação maior, como apresentado a seguir:

Apenas no currículo escolar das universidades. Que eu saiba não tem estudos do próprio município para o idoso. (Anil)

Não, não... Assim, que eu conheça... Pesquisa... Que eu saiba não. Nada. (Vermelho)

Aqui a gente tem trabalhado muito em consonância com a pesquisa porque é portaria, e porque é necessidade (...). Os profissionais foram liberados para esta atividade. (Amarelo)

\section{E. Promoção à saúde e prevenção de doenças e agravos}

Neste tópico, listamos as atividades descritas pelos entrevistados que são realizadas nos Centros de Saúde que visam promover a saúde, prevenção de doenças e agravos, bem como a reabilitação. Na avaliação dos gestores, a questão da promoção foi o que mais avançou no município em termos de práticas em saúde:

Então neste ponto a gente tem bastante oferta (...). Mas eu acho que neste ponto, da questão da preventiva, a gente tem trabalhado bem; acho que é uma das coisas que mais andou, em termos de saúde do idoso, mesmo. (Verde)

Avançou bastante, principalmente na saúde integrativa, eu acho que é um trabalho que o idoso também precisa muito. (Vermelho)

As atividades citadas pelos gestores foram classificadas conforme segue:

Práticas integrativas: meditação, homeopatia, plantas medicinais;

Atividades de Vivência (não corporais): artesanato, Tear das Artes, bailes, excursões, Viva Mais (programa que tem como principal objetivo estimular a participação dos idosos numa rede de ações que possibilitam conhecer novos amigos e ampliar as perspectivas de vida);

Grupos: Educação em Saúde, Qualidade de Vida, Hiperdia, Reeducação Alimentar;

Atividades corporais - que visam predominantemente o exercício físico: Lian Gong (prática corporal oriental que objetiva tratar e prevenir dores no corpo, problemas osteomusculares e articulares e atua nas disfunções dos órgãos internos e problemas respiratórios), Tai Chi Chuan (é uma arte marcial chinesa, reconhecida também como uma forma de meditação em movimento) ginástica corporal, ginástica harmônica, dança circular, ginástica postural, caminhada.

Apesar de afirmarem o avanço do município dentro das práticas de promoção, alguns gestores ressaltam a falta de envolvimento dos profissionais com estas atividades. Trazem ainda a importância dos grupos para a diminuição da demanda espontânea:

Com o grupo (...) você tira paciente de agenda! Essa coisa do paciente voltar, voltar e voltar, você tira ele disso! (...) Você informa mais, orienta mais, o paciente controla meIhor (...). Isso a gente não vê na prática (...) Aqui nós ainda não entendemos, pelo menos a maioria, ainda não incentivam a criação desta questão de grupos. (Laranja)

A população e os profissionais têm dificuldade em incorporar isso. Nós trabalhadores, por conta da formação, é uma das questões, porque a gente é de uma geração diferente... Eu (...) venho de outra geração, absolutamente hospitalocêntrica, voltada para assistência. Então os próprios profissionais hoje têm dificuldade em entender o valor das ações de promoção. (Violeta)

No entanto, alguns deles trazem a ideia de que muitas das atividades realizadas são pontuais e não são específicas para o idoso. Apenas um sujeito demonstrou haver uma iniciativa de diferenciar, na prática, o idoso do adulto. E em muitas das atividades, por não serem específicas para o idoso, acabam não vendo o idoso de forma integral, apesar de a grande maioria dos participantes serem idosos:

Algumas unidades têm grupos específicos de artesanato... Mas é bem pontual. (Verde) 
Então todas as atividades (...) são direcionadas para o adulto e o idoso está participando. Não tem alguma coisa separada, não tem esta separação ainda na maioria das unidades (...) tudo o que é desenvolvido para o adulto, o idoso é super presente. A maioria são idosos. (Vermelho)

Então a gente tenta fazer uma primeira consulta do idoso um pouco mais demorada, ou, por exemplo, na farmácia, a gente orienta a auxiliar a checar se o paciente entendeu a maneira correta de tomar a medicação (...) que com o idoso ela tenha um pouco mais de atenção (...) em todas as ações dentro das nossas unidades a gente tenta trazer um pouco deste olhar. (Violeta)

\section{F. Gestão}

Este tópico apareceu relacionado com muitas outras questões, tais como recursos humanos, práticas de promoção à saúde, manejo da demanda, infra-estrutura, dentre outros. E quando questionados a respeito de alternativas para viabilizar as políticas na prática, a maioria dos gestores destacam a "verba insuficiente" para as ações em saúde e os desdobramentos que isto tem:

O passo inicial que eu acho é o recurso público. Não tem outro caminho. (...) Não tem outro caminho para atender aos que mais precisam. (Anil)

Então eles criaram as portarias (...) mas não deram verba. Então fica difícil, fica por conta do município. (Amarelo)

(...) tem muitas coisas que a gente não faz. Passa pela questão do financiamento e todos os desdobramentos que isto tem. Por exemplo: a contratação de ACS: como que você quer organizar a saúde do idoso numa população com quatro ACS? O clínico generalista com uma agenda lotada todo dia. Então é assim: o dinheiro e todos os desdobramentos operacionais disso (...). Se a gente tivesse um centro de saúde lindo, muito dinheiro e uma gente tropeçando, não garantem também... Então eu acho que aí entram as outras questões (...), que são, primeiro, no nível de gestão, macro mesmo, desde assim, a nossa carreira de coordenador, dos gestores (...). A capacitação, como é feita? Quem são os nossos gestores hoje? (Violeta)

A questão da referência para o Centro de Referência do Idoso (CRI) por parte de alguns distritos, pois deve haver orientação das unidades e pelo atendimento aos usuários ser feito apenas por encaminhamento:

Você tem um CRI que começou e que teria que ter começado depois, porque você teria que ter os centros de saúde com atendimento bom ao idoso para então ter o CRI. A gente não pode fazer encaminhamento nenhum. Por enquanto não temos isto... (Azul)

O CRI faz dois anos que está na ativa (...) e capacitou as unidades do distrito $W$ para encaminharem estes pacientes ao
CRI. A demanda espontânea lá não acontece. Nem mesmo acolhimento. Apenas com referência. (Verde)

Além disso, ressaltam a necessidade de sustentabilidade, intersetorialidade e institucionalização das ações em saúde:

Em qualquer serviço hoje a palavra que tem que ter é sustentabilidade; e tem que ser independente daquela pessoa que está administrando naquele momento. (...) Tem que ser uma coisa institucionalizada dentro do programa de saúde; não é só um programa, uma campanha; tem que ser permanente. (Anil)

Eu acho que a gente precisa de uma coisa bem ampla, de envolver outras políticas, de melhorar, aí, a nossa capacidade de articulação, né, da saúde com as outras áreas. Para gente poder potencializar as nossas ações. (Violeta)

Outras questões pontualmente citadas foram a falta de uma política avaliativa das ações, de autonomia para os distritos, e de um centro de educação permanente para cada distrito para, assim, facilitar a formação e desenvolvimento de estudos na área do envelhecimento. Além disso, alguns gestores mostraram-se confusos no momento de responder algumas questões, evidenciando dificuldade de entender a política de saúde do idoso e, consequentemente, de se implementar práticas convergentes com tais diretrizes.

\section{DISCUSSÃO}

As políticas nacionais referentes à saúde do idoso foram criadas a partir de 1994 e vêm tendo repercussão aos poucos na rede de saúde, pois enquanto nos países desenvolvidos o envelhecimento ocorreu associado às melhorias nas condições gerais de vida, nos países em desenvolvimento esse processo acontece de forma rápida, sem tempo para uma reorganização social e da área de saúde adequada para atender às novas demandas emergentes ${ }^{(1)}$. Isso justifica a opinião dos sujeitos quando dizem que a atenção à saúde do idoso em Campinas é um programa novo e que ainda está em desenvolvimento.

De acordo com os discursos dos gestores, os idosos e suas famílias parecem não encontrar nas unidades básicas de saúde de Campinas o apoio e resolutividade de que necessitam. No entanto, sabe-se que a atenção primária deve ser o primeiro contato ou principal porta de entrada do sistema de saúde que visa garantir atenção à maior parte das necessidades de saúde, bem como indicar o acesso aos outros níveis, quando preciso. Para o sistema funcionar desta forma é preciso que a unidade básica de saúde seja acessível à população adscrita, eliminando-se barreiras financeiras, geográficas, temporais e culturais, aspectos em geral que deveriam ser contemplados pelo Programa de Saúde da Família(11).

A universalidade é restrita também pela falta de investimentos que compatibilizem a oferta com o aumento substancial da demanda à saúde, e em decorrência da perda da qualidade dos serviços prestados, experimenta um processo sutil de privatização ${ }^{(12)}$. 
As altas demandas revelam uma mescla de direitos, necessidades e desejos, que assumem conotações distintas, de acordo com um processo dialógico ${ }^{(13)}$. Entende-se com isso que a integralidade assume um papel referencial dentro do sistema de saúde e que sua completude é quase impossível de ser alcançada, visto que está relacionada aos sentimentos e necessidades do outro, que são subjetivos e volúveis. No entanto, é preciso tentar superar limites para se aproximar do que se diz ser a integralidade do cuidado, trazendo para a discussão tais barreiras a fim de sejam ou possam ser ultrapassadas, pois os idosos e suas famílias necessitam ser compreendidos e apoiados, considerando a complexidade do trabalho em saúde.

No que tange à integralidade, a atenção integral em saúde se volta para as necessidades do ser humano como sujeito da produção da existência, sendo que a satisfação de tais necessidades nos orienta na construção de relações sociais. Não há como pensar e realizar o trabalho de um ser humano integralmente se não nos reconhecermos também como ser integral. Esse princípio precisa estar presente na formação desses trabalhadores $^{(14)}$.

Um processo de trabalho apoiado em uma equipe multiprofissional apta a oferecer atenção integral e a sustentar o enfoque ampliado da estratégia de saúde da família, com claros objetivos de inclusão social, exige qualificação dos profissionais inseridos e adesão ao programa por parte desses profissionais ${ }^{(15)}$. Conforme pode ser constatado pelos resultados, a formação dos profissionais com vista a fazê-los perceber a integralidade do idoso é insuficiente. Tais dilemas deveriam, portanto, ser compreendidos pelos gestores a fim de que buscassem superar, no dia-a-dia, a alienação no e pelo trabalho que se manifesta pela divisão de tarefas ou em áreas diversas e distintas do saber, principalmente no cuidado aos idosos ${ }^{(14)}$.

Quanto às práticas de saúde, a conversão do modelo de atenção básica operacionaliza-se por meio da organização do trabalho em equipe, com a substituição de práticas convencionais de assistência e a incorporação de novas práticas voltadas para a família e a comunidade, com o objetivo de influenciar os determinantes sociais do processo saúde-doença ${ }^{(16)}$. No entanto, pôde-se perceber pelos relatos que esta ideia tem sido incorporada por poucos profissionais da saúde do município, exceto pelo dever do seguimento da política, no sentido de obrigação a seguir. Exemplo disso é o fato de alguns gestores trazerem a questão do esforço dos ACS para formarem grupos, enquanto os profissionais da saúde estão dentro do Centro de Saúde atendendo à demanda espontânea.

Como uma alternativa, a integração das unidades de atenção primária à rede assistencial como forma de garantir oferta abrangente de serviços e para coordenar as diversas ações requeridas para resolver as necessidades menos frequentes e mais complexas da população ${ }^{(11)}$. A coordenação deste serviço implica a capacidade de garantir a continuidade da atenção ao longo da rede de serviços por meio de mecanismos de integração, tecnologias de gestão clínica e instrumentos para a comunicação entre profissionais de diferentes serviços. Neste sentido, a intersetorialidade levaria a uma melhor resolutividade dos problemas de saúde da população.

A efetivação da atenção básica como estratégia de reorganização do modelo assistencial depende de sua transformação num nível de atenção de alta resolubilidade, qualidade e capacidade de integração com os demais níveis do sistema ${ }^{(17)}$. O Programa Nacional de Melhoria do Acesso e da Qualidade da Atenção Básica (PMAQ) ${ }^{(18)}$ confirma esta ideia, na medida em que busca induzir a ampliação do acesso e a melhoria da qualidade da atenção básica, com garantia de um padrão de qualidade comparável nos diversos âmbitos local, regional e nacional, de maneira a permitir maior transparência e efetividade das ações governamentais direcionadas à atenção básica em saúde em todo o Brasil.

Pôde-se perceber, portanto, que o modelo de atenção à saúde do idoso em Campinas, de acordo com o discurso dos sujeitos, é fragmentado e desigual, trazendo fortes entraves para a consolidação efetiva e plena das políticas de saúde a este grupo etário, condicionando e determinando questões centrais como a rede de atenção, sua utilização, o acesso dos usuários aos serviços, os recursos, impactando os próprios princípios do $\mathrm{SUS}^{(12)}$.

\section{CONSIDERAÇÕES FINAIS}

Este estudo traz a visão dos gestores da área da saúde do idoso da cidade de Campinas sobre a implementação de ações voltadas à saúde do idoso no município, com base na PNSPI. O método de livre discurso por parte dos gestores, direcionada apenas pelas questões relacionadas às diretrizes, proporcionou às pesquisadoras um conteúdo rico, pois os sujeitos tiveram a liberdade de opinar acerca da construção da saúde do idoso em Campinas, além do relato das ações que de fato já foram concretizadas na cidade. No entanto, foi considerada uma limitação do estudo o fato de um dos distritos não ter sido avaliado, pois o responsável pela área de atuação estava em férias.

Partindo do pressuposto da descentralização preconizada pelo SUS, o município é responsável pela criação e manutenção de unidades de atenção à saúde, bem como pela articulação entre elas, garantindo a resolutividade e sustentabilidade dos serviços prestados, bem como, pela prestação de contas aos governos estadual e federal e à população do adequado funcionamento destas atividades. Operar o SUS com equidade e garantindo atenção a todos, com ênfase aos mais frágeis, é um desafio permanente.

Conforme o discurso dos gestores, o município de Campinas parece estar aquém do desejado. No entanto, observa-se que o município tem investido nas ações em prol do idoso, e tem tentado colocar em prática a Política Nacional de Saúde do Idoso. Os entraves citados parecem estar relacionados às diferentes esferas de gestão: municipal, estadual e federal. Identificou-se a necessidade de se promover ações avaliativas das atividades já instaladas e que estas sejam mais bem planejadas, conforme as necessidades reais do idoso e do sistema de atenção à saúde como um todo.

Deve-se ressaltar que não há representantes da Enfermagem em cargos diretivos na gestão municipal de serviços voltados 
para a pessoa idosa. A partir dos resultados do presente estudo e considerando a enfermagem como disciplina voltada para o cuidado humano e o ensino do autocuidado, pode-se encontrar lacunas das práticas na saúde do idoso passíveis de serem minimizadas a partir de iniciativas dos profissionais da área, que propiciem melhorias na assistência a estas pessoas, melhor qualidade de vida, manutenção da autonomia e independência.

\section{REFERÊNCIAS}

1. Ministério da Saúde. Cadernos de atenção básica: EnveIhecimento e saúde da pessoa idosa. Normas e Manuais Técnicos (19). Brasília: MS; 2007.

2. Schmidt MI, Duncan BB MD, Silva GA, Menezes AM, Monteiro CA, Barreto SM, et al. Chronic non-communicable diseases in Brazil: burden and current challenges. Lancet 2011;377(9781):1949-61.

3. IBGE [homepage na internet] Pesquisa Nacional por Amostra de Domicílios (2008). Um panorama da Saúde no Brasil: acesso e utilização dos serviços, condições de saúde e fatores de risco e proteção à saúde; 2010. [acesso em 04 de dezembro de 2012]. Disponível em: < http://biblioteca.ibge.gov.br/visualizacao/monografias/GEBIS\%20-\%20RJ/panorama.pdf >

4. Ribeiro CDM, Schramm FR. A necessária frugalidade dos idosos. Cad Saúde Pública 2004;20(5):1141-8.

5. Drachler ML, Côrtes SMV, Castro JDC, Leite JCC. Proposta de metodologia para selecionar indicadores de desigualdade em saúde visando definir prioridades de políticas públicas no Brasil. Ciênc Saúde Coletiva 2003;8(2):461-70.

6. MLC, Souza ER, Lima MLLT, Barreira AK, Bezerra ED, Acioli RML. Assistência à saúde dos idosos vítimas de acidentes e violência: uma análise da rede de serviços SUS no Recife (PE, Brasil). Ciênc Saúde Coletiva 2010;15(6):2677-86.

7. Ministério da Saúde (Brasil) Portaria $n^{\circ}$. 2.528. Política Nacional de Saúde da Pessoa Idosa. Diário Oficial da União 19 out 2006.

8. Brasil. Lei $\mathrm{n}^{\circ} 10.741$ de $1^{\circ}$ de outubro de 2003. Dispõe sobre o Estatuto do Idoso. Diário Oficial da União; 3 out 2003.

9. Rodrigues RAP, Kusumota L, Marques S, Fabrício SCC,
Cruz IR, Lange C. Política nacional de atenção ao idoso e a contribuição da Enfermagem. Texto \& Contexto Enferm 2007; 16(3):536-45.

10. Minayo MCS. O desafio do conhecimento: pesquisa qualitativa em saúde. 8. ed. São Paulo: Hucitec; 2004.

11. Starfield B. Atenção primária: equilíbrio entre necessidades de saúde, serviços e tecnologia. Brasília: UNESCO, Ministério da Saúde; 2002, p.726.

12. Heiman LS, Ibanhes LC, Barboza R, organizadores. O público e o privado na saúde. São Paulo: Hucitec; 2005.

13. Spink MJP. Sobre a possibilidade de conciliação do ideal da integralidade nos cuidados à saúde e a cacofonia da demanda. Saúde Soc 2007;16(1):18-27.

14. Ramos M. Educação pelo trabalho: possibilidades, limites e perspectivas da formação profissional. Saúde Soc 2009;18(2):55-9.

15. Escorel S. O Programa de Saúde da Família e a construção de um novo modelo para a atenção básica no Brasil. Rev Panam Salud Publica 2007;21(2):164-76.

16. Ministério da Saúde, Secretaria de Políticas de Saúde. Avaliação da implementação do Programa Saúde da Família em dez grandes centros urbanos: síntese dos principais resultados. Brasília: MS; 2002.

17. Castanheira ERL, Dalben I, Almeida MAS, Puttini RF, Patrício KP, Machado DF, et al. Avaliação da Qualidade da Atenção Básica em 37 Municípios do Centro-Oeste Paulista: características da organização da assistência. Saúde Soc $2009 ; 18(2): 84-8$.

18. Ministério da Saúde (Brasil). Portaria no 1.654 de 19 de julho de 2011. Programa nacional de melhoria do acesso e da qualidade da atenção básica (PMAQ). Diário oficial da União 12 jul 2011. 